\title{
Reduced extinction of hippocampal-dependent memories in CPEB knockout mice
}

\author{
Joanne Berger-Sweeney, ${ }^{1}$ N. Ruth Zearfoss, ${ }^{2}$ and Joel D. Richter ${ }^{2,3}$ \\ ${ }^{1}$ Department of Biology, Wellesley College, Wellesley, Massachusetts 02481, USA; ${ }^{2}$ Program in Molecular Medicine University \\ of Massachusetts Medical School, Worcester, Massachusetts 01605, USA
}

\begin{abstract}
CPEB is a sequence-specific RNA binding protein that regulates translation at synapses. In neurons of CPEB knockout mice, synaptic efficacy is reduced. Here, we have performed a battery of behavioral tests and find that relative to wild-type animals, CPEB knockout mice, although similar on many baseline behaviors, have reduced extinction of memories on two hippocampal-dependent tasks. A corresponding microarray analysis reveals that about $0.14 \%$ of hippocampal genes have an altered expression in the CPEB knockout mouse. These data suggest that CPEB-dependent local protein synthesis may be an important cellular mechanism underlying extinction of hippocampal-dependent memories.
\end{abstract}

The modulation of synaptic strength, which underlies long-term memory storage (Hering and Sheng 2001), may involve "synaptic tagging," where a stimulated synapse is tagged with a molecular mark that a neuron uses to distinguish naive from stimulated synapses (Martin et al. 2000). Based on the recognition of this tag, a neuron can modify the strength of its synaptic response upon subsequent stimulation. While the nature of the tag is unknown, protein synthesis is involved in its establishment or recognition (Kang and Schuman 1996; Huber et al. 2000; Scheetz et al. 2000; Richter and Lorenz 2002). One process that regulates translation at synapses is cytoplasmic polyadenylation; here, mRNAs have short poly(A) tails, but in response to activity, the poly(A) tails lengthen and translation ensues (Wu et al. 1998; Huang et al. 2002; Du and Richter 2005). CPEB is the factor responsible for polyadenylation; it is a sequence-specific RNA binding protein that once phosphorylated, activates a series of events that culminates in polyadenylation and translation (Mendez et al. 2000; Barnard et al. 2004; Sarkissian et al. 2004).

In neurons, $N$-methyl-D-aspartate receptor (NMDAR) signaling mediates CPEB phosphorylation and resulting polyadenylation (Wu et al. 1998; Huang et al. 2002; Shin et al. 2004; Du and Richter 2005). The importance of CPEB is underscored by experiments showing that knockout (KO) mice have a deficit in longterm potentiation (LTP) in Schaffer collateral CA-1 hippocampal neurons stimulated with a theta-burst protocol (Alarcon et al. 2004). Here, we have examined the behavior of CPEB-knockout mice. The animals have normal motor and sensory function but exhibit alterations in reversal learning of a spatial navigation task, as well as reduced extinction in hippocampal-dependent memory tasks. In the hippocampus, CPEB regulates the expression of about $0.14 \%$ of genes. These data show that CPEB modifies not only gene expression and synaptic plasticity, but learning and memory as well.

The generation of CPEB knockout (KO) mice has been described (Tay and Richter 2001). Physical evaluation and behavioral testing on 3-4-mo-old C57Bl/6 males (10 WT and $10 \mathrm{KO}$ ) included visual observation, weighing, forepaw grip strength (grip strength apparatus, San Diego Instruments) (Frick et al. 2000), rotorod motor coordination (San Diego Instruments), $12 \mathrm{~h}$ dark cycle locomotor activity (Arters et al. 1998) using a Photobeam Activity System (San Diego Instruments), anxiety and exploratory behaviors on a zero maze (Pähkla et al, 2000), multi-

\footnotetext{
${ }^{3}$ Corresponding author.

E-mail joel.richter@umassmed.edu; fax (508) 856-4289.

Article and publication are at http://www.learnmem.org/cgi/doi/10.1101/ Im.73706.
}

day water maze acquisition and extinction tasks, hearing evaluation (Preyer's reflex), contextual fear conditioning and extinction, and shock sensitivity testing. A second set of animals ( $9 \mathrm{WT}, 10 \mathrm{KO}$ ) was assessed for contextual fear conditioning retention $10 \mathrm{~d}$ after initial acquisition. In all cases, the experimenters were blind to genotypes. All mice were maintained on a 12-h light/12-h dark cycle with food and water available ad libitum except during testing.

Spatial and cued learning, memory, and extinction were tested using multi-day water maze paradigms (Lattal and Abel 2001). During spatial acquisition trials (7 d), the mice locate a hidden platform using extra maze visual cues. The animals received four spatial trials/day for $7 \mathrm{~d}$; a maximum of $60 \mathrm{sec} /$ trial was allowed with a 4-6 min inter-trial interval (ITI). During the reversal trials $(4 \mathrm{~d})$ the hidden platform was moved to a new quadrant and the mice learned to locate the new platform position. During reacquisition trials $(4 \mathrm{~d})$, the hidden platform was moved back to the original training quadrant and the mice relearned to locate this position. During extinction trials $(6 \mathrm{~d})$, the platform was removed and the amount of time the animals spent in the original platform quadrant was recorded. Thirty minutes after the third block of spatial trials, the mice received one probe trial in which the platform initially was lowered to make it unavailable for escape. Thirty seconds were allowed for the mouse to attempt to locate the platform, then the platform was raised and another $30 \mathrm{sec}$ was allowed for the mouse to locate and climb onto it. Finally, the extra-maze cues were removed and the location of a visible platform was changed to a different quadrant for each of four cued trials. Parameters for spatial and cued trials were swim time, path length, and swim speed.

A chamber containing an infrared beam that detects animal movement (Coulbourn Instruments Habitest System) was used to measure contextual fear conditioning under constant light. For the acquisition phase, a mouse was placed in a chamber with an electrified floor grid (context A). The mouse was given two consecutive training trials, each consisting of a 2-min acclimation period, the sounding of an 80-dB white noise tone for $30 \mathrm{sec}$, and the administration of a 2 -sec $0.5-\mathrm{mA}$ foot shock concomitant with the last $2 \mathrm{sec}$ of the tone. After the second training trial, the mouse was monitored for an additional $30 \mathrm{sec}$, and then returned to its home cage. To measure context memory $24 \mathrm{~h}$ after the regimen noted above, the mouse was placed again in the same chamber for $5 \mathrm{~min}$ and its movement monitored; however, no shock was given. The various test segments were separated into bins of $10 \mathrm{sec}$ duration, and the percent time spent freezing in each of the bins was calculated. Freezing was defined as $\geq 3$ continuous sec during which no movement was detected. The per- 
Table 1. Baseline behavioral characteristics

\begin{tabular}{llccc}
\hline Task & Characteristic tested & WT & KO & SD \\
\hline Reaching & reflex & normal & normal & - \\
Righting & reflex & normal & normal & - \\
Body weights (g) & & $27.8 \pm 1.4$ & $27.1 \pm 0.9$ & ND \\
Grip strength (g) & forepaw & 6060 & ND & ND \\
Zero maze (\% time open arms) & exploratory & $15.2 \pm 6.2$ & $18.7 \pm 7$ & ND \\
Rotorod (sec to fall) & motor coordination & $90.6 \pm 5$ & $93.0 \pm 3$ & ND \\
Photobeam breaks & locomotor activity & $5548 \pm 601$ & $4998 \pm 761$ & normal \\
Preyer's reflex & hearing & normal & normal & - \\
Shock reactivity & sensitivity to pain & normal & &
\end{tabular}

WT = wild-type; $\mathrm{KO}=$ knockout; $\mathrm{SD}=$ significant difference; $\mathrm{ND}=$ no significant difference observed $(P>0.05)$.

cent freezing for each part of the test was determined by averaging the percent freezing calculated for each of the associated bins. Extinction trials were identical to conditioning acquisition trials except that no shock was presented. The mouse received two extinction trials, with a 20-min ITI on d 2, 3, 4, and 9 after the acquisition trials. To measure $9-\mathrm{d}$ retention, one set of mice received fear conditioning acquisition training exactly as described previously, however, contextual memory retention was assessed $9 \mathrm{~d}$ (rather than $24 \mathrm{~h}$ ) later. These mice did not receive extinction trials.

Shock reactivity was tested as previously described (Arters et al. 1998). Mice were given a series of 1-sec foot shocks of increasing intensities $(0.05 \mathrm{~mA}, 0.1 \mathrm{~mA}, 0.15 \mathrm{~mA}$, and $0.2 \mathrm{~mA})$. Vocalizations and jumping were scored on a $0-3$ scale ( 0 indicated no response and 3 indicated an extreme response). As a measure of gross hearing loss, Preyer's reflex was examined (Jero et al. 2001). Data were analyzed using Student $t$-tests, one- or two-factor ANOVA or repeated measures ANOVA using SuperANOVA (Abacus Concepts, Inc). Shock reactivity scores were analyzed using the Mann-Whitney test for nonparametric data using SPSS data analysis software (SPSS, Inc.).

Table 1 summarizes several neurological, locomotor activity, sensory, and anxiety measurements. In all cases, wild-type (WT) and CPEB knockout (KO) mice were statistically indistinguishable.

Spatial navigation tasks (acquisition, reversal, and reacquisition of a platform position), which are hippocampusdependent (Morris et al. 1982), were followed by extinction trials and finally cued/visible platform trials (Frick and Berger-Sweeney 2001). Both groups of mice learned the position of the platform as noted by decreased latencies over the $7 \mathrm{~d}$ of the acquisition trials (Fig. 1A); overall, the swim latencies for WT and KO mice did not differ $\left[F_{(1,18)}=3.5, P=0.08\right]$. However, on $\mathrm{d} 1-4$, the $\mathrm{KO}$ mice had significantly lower latencies $\left[F_{(1,18)}=5.4, P=0.03\right]$, suggesting a faster rate of learning. During reversal trials, when the platform was moved to the quadrant opposite the original training quadrant, both groups had long latencies on the first day as evidenced by their perseveration in the original training quadrant. While latencies for both WT and KO mice decreased similarly on $\mathrm{d} 2$, there were different patterns in reversal performance between the groups $\left[F_{(3,54)}=9.5, P=0.0001\right]$. Retentions of the different tasks, as measured in the probe trials, were similar between WT and KO.

During the 5-d water maze extinction trials, the platform was removed and the percent time in the former training quadrant was measured. The WT mice extinguished the preference for the former platform quadrant more quickly than the KO mice $\left[F_{(1,18)}=4.3, P=0.05\right]$ despite the fact that there were no significant differences in performance on the first day of extinction trials $\left[t_{(18)}=1.7, P=0.1\right]$, (Fig. 1B). While the WT mice extinguished to chance performance $(25 \%)$ by d 4 , the KO mice had not reached chance performance even by $\mathrm{d} 5$.

Cued (visible platform) trials were run on the last day of swim-maze testing. Both groups learned the cued task as indicated by decreased latencies over the four blocks of trials (data not shown). There were no significant differences between groups or significant interactions [ $\left.F^{\prime} \mathrm{s}<2.5, P^{\prime} \mathrm{s}>0.13\right]$, suggesting the two groups had similar visual abilities and motivations to find the platform and climb onto it to escape swimming (Fig. 1B).

Both groups of mice exhibited little freezing in the conditioning chamber before any shock was presented $(10.2 \pm 5.4 \%$ freezing in the WT and $9.7 \pm 4.3 \%$ in the KOs) $\left[t_{(18)}=0.005, P=0.9\right]$. Twentyfour hours after the acquisition session in which the mice received shocks, both groups responded to being placed back in the context where they had received shocks with increased freezing $78.4 \pm 3.6 \%$ and $86.4 \pm 2.8 \%$ freezing, respectively (Fig. 1C). While there was no significant difference between the groups on $\mathrm{d} 1\left[t_{(18)}=1.9, P=0.07\right]$, over the entire $9 \mathrm{~d}$ of testing, the WT extinguished more quickly than the $\mathrm{KO}\left[F_{(1,18)}=6.0, P=0.03\right]$.

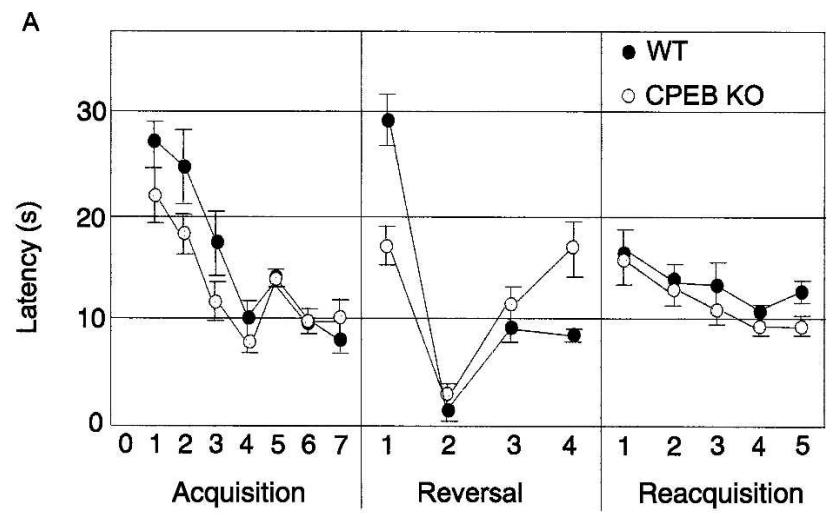

B
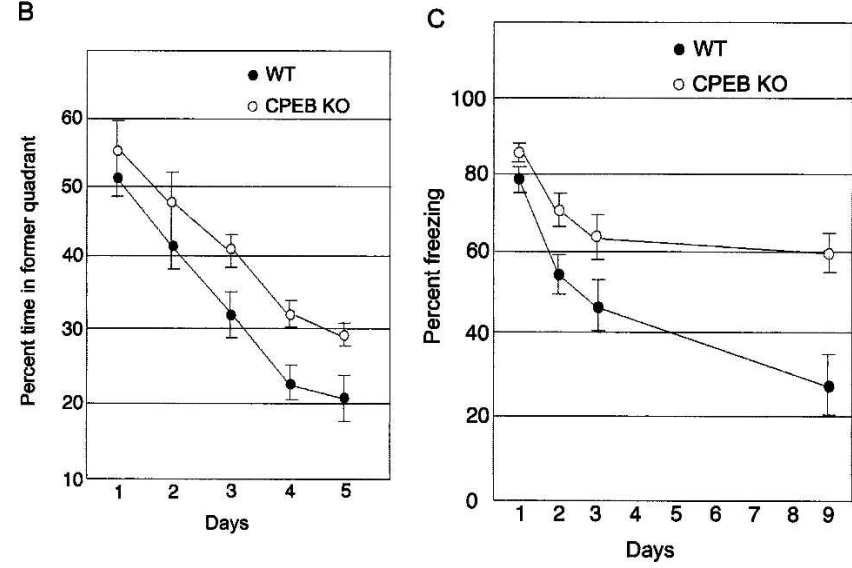

Figure 1. Behavioral analysis. (A) Swim-maze performance. Shown here is the latency to find the hidden platform on the swim-maze trials during $7 \mathrm{~d}$ of acquisition, $4 \mathrm{~d}$ of reversal and $5 \mathrm{~d}$ of reacquisition. Mean latencies \pm S.E.M. are shown for WT and CPEB KO mice. (B) Extinction of the swim-maze task. Shown here is the percent time spent in the former training (hidden platform) quadrant on successive days of extinction testing. Mean percentages \pm S.E.M. are shown. (C) Extinction of contextual fear conditioning. Shown here is the percent freezing in a chamber in which the mice had previously received a shock in the extinction phase of contextual fear conditioning trials. Mean percentages \pm S.E.M. are shown. 
To measure contextual fear conditioning retention, mice acquired the fear conditioning task; fear conditioning retention was measured $9 \mathrm{~d}$ later, which was similar between the groups$70.3 \% \pm 8.1$ for WTs and $73.0 \% \pm 10.3$ for $\mathrm{KOs}\left[t_{(15)}=0.5\right.$, $P=0.6]$. These data suggest that the KO mice had impaired extinction, but normal retention, of the task.

Because the behaviors noted above require hippocampal function (Sanders et al. 2003), we determined whether gene expression in this area of the brain is altered in CPEB KO mice. DNA arrays covering $\sim 36,000$ sequences (U74v2 Affymetrix) were probed with cRNA derived from the hippocampi of 2-3-mo-old WT and CPEB KO mice. The array was probed with four samples containing pooled RNA from two WT or two KO hippocampi; because each WT sample was compared to each KO sample, there were four comparisons for each gene. The data were analyzed according to Affymetrix statistical algorithms. RNA changes between WT and KO were considered to be significant if there was a twofold or more difference in at least three of the four comparisons. Quantitative RT-PCR using SYBR Green (Qiagen) was also used to compare selected sequences.

The expression of only 19 genes was different between the two samples (Table 2 ), representing $\sim 0.14 \%$ of the $\sim 14,000$ hippocampal sequences on the array; 15 of the RNAs decreased by 2-28-fold in the KO versus WT while four were increased from $\sim 4-14$-fold. Three of the RNAs, transthyretin, Enpp2, and Fut9 were further examined by quantitative RT-PCR and found to be decreased in the KO compared to WT, thus confirming the microarray results. Surprisingly, only about one-third of the RNAs have obvious CPEs. The products of these sequences have a variety of functions ranging from transcription factors to ion channels to a hormone transport factor. Interestingly, at least two of the factors, TTR (Stork et al. 2001; Sousa et al. 2004; Stein et al. 2004) and NPAS2 (Garcia et al. 2000), have been implicated in learning and memory.

The most consistent cognitive change in the CPEB KO mice is an impaired ability to extinguish memories. Extinction refers to a behavioral response that will diminish and gradually become extinct in the absence of reinforcement. Numerous studies indicate that extinction results in the formation of new memories, and is not equivalent to forgetting. The mechanisms underlying extinction can be distinct from those underlying acquisition and storage of memories (Abel and Lattal 2001). On the swim task, the $\mathrm{KO}$ mice extinguished the memory of the hidden platform more slowly than WT mice, despite similar performance on the first day of the extinction trials. Similarly, the KO mice extinguished the memory of a fearful context more slowly than WT, despite similar performance on the first day of the extinction trials. In the fear condition task, KO mice showed similar retention of the fearful stimulus, if extinction trials did not take place. These data point to impaired extinction in the CPEB KO mice, despite normal retention across two behavioral tasks that employ different types of learning, motivation, and motor skills. We should also point out that because we used a global knockout mouse for our studies, the impairment of memory extinction could also be due to developmental defects.

The microarray analysis detected few changes in gene expression in the CPEB KO hippocampus. Some of the changes probably represent secondary effects of the loss of CPEB since many of the RNAs do not contain CPEs. However, because CPEB regulates translation, there may be several RNAs whose expression, but not steady state levels, are adversely affected by the loss of this protein (Du and Richter 2005). Nonetheless, some of the sequences that decreased in the CPEB KO hippocampus are known to have important neural functions. NPAS2 has been implicated in contextual fear conditioning and TTR has been shown to promote behavior similar to that seen in depression (Sousa et al. 2004; Stein et al. 2004). Sclerostin domain containing protein 1 is an inhibitor of bone morphogeneic proteins (BMPs) (Laurikkala et al. 2003), which promote dendritogenesis (Lein et al. 2002). In addition, ectonucleotide pyrophosphatase phosphodiesterase 2 (Enpp2) produces lysophosphatidic acid, which functions in brain development (Moolenaar et al. 2004), and peptidyl

Table 2. Genes with altered expression in CPEB knockout mice

\begin{tabular}{|c|c|c|c|c|c|}
\hline GenBank ID & Description & $\begin{array}{l}\text { Change } \\
\text { direction }\end{array}$ & Fold change & CPE & Common function \\
\hline D00073 & Transthyretin (Ttr) & $\mathrm{D}$ & $\begin{array}{l}9.4 \pm 4.1 \\
\left(20^{\mathrm{a}}\right)\end{array}$ & Yes & thyroid hormone transport \\
\hline U77969 & Neuronal PAS domain protein 2 (Npas2) & $\mathrm{D}$ & $7.2 \pm 0.6$ & No & transcription factor \\
\hline U52925 & Coagulation factor $\mathrm{V}$ & $\mathrm{D}$ & $4.3 \pm 1.9$ & No & coagulation \\
\hline AW122933 & $\begin{array}{l}\text { Ectonucleotide pyrophosphatase phosphodiesterase II } \\
\text { (Enpp2) }\end{array}$ & $\mathrm{D}$ & $\begin{array}{l}2.2 \pm 0.1 \\
\left(2.5^{a}\right)\end{array}$ & Yes & unknown \\
\hline AB015426 & Alpha1,3-fucosyltransferase IX (Fut9) & $\mathrm{D}$ & $2.2 \pm 0.5$ & Yes & $\begin{array}{l}\text { neural development, carbohydrate } \\
\text { synthesis }\end{array}$ \\
\hline Al841913 & Sclerostin domain containing protein 1 (Sostdc1) & $\mathrm{D}$ & $2.8 \pm 0.5$ & Yes & $\begin{array}{l}\text { bone morphogenic protein (BMP) } \\
\text { inhibitor }\end{array}$ \\
\hline AW045520 & Chloride intracellular channel 6 (Clic6) & $\mathrm{D}$ & $3.2 \pm 0.4$ & No & channel protein \\
\hline AW048273 & $\begin{array}{l}\text { Potassium voltage-gated channel, Isk-related subfamily, } \\
\text { gene } 2 \text { (Kene2) }\end{array}$ & $\mathrm{D}$ & $\begin{array}{c}28.7 \pm 9.3 \\
\left(2.6^{\mathrm{a}}\right)\end{array}$ & Yes & channel protein \\
\hline Al786414 & EST_-similar to Transthyretin & $\mathrm{D}$ & $2.6 \pm 0.6$ & No & see above \\
\hline AV259193 & EST & $\mathrm{D}$ & $6.6 \pm 4.6$ & No & unknown \\
\hline AW122611 & Similar to Family with sequence similarity 40 member B & $\mathrm{D}$ & $2.7 \pm 1.2$ & No & unknown \\
\hline AU021218 & Neuronal PAS2 & $\mathrm{D}$ & $2.5 \pm 0.7$ & No & see above \\
\hline AV311906 & EST & $\mathrm{D}$ & $2.8 \pm 0.5$ & No & unknown \\
\hline AV268551 & EST & $\mathrm{D}$ & $9.5 \pm 0.9$ & Yes & unknown \\
\hline AV154863 & EST & $\mathrm{D}$ & $2.7 \pm 1.2$ & No & unknown \\
\hline U79523 & Peptidylglycine alpha-amidating monooxygenase (Pam) & I & $9.4 \pm 6.9$ & No & neuropeptide processing \\
\hline D14636 & Core binding factor alpha 1 & I & $4.8 \pm 2.3$ & Yes & transcription factor \\
\hline $\mathrm{Al} 595843$ & EST & I & $14.3 \pm 10.9$ & No & unknown \\
\hline Al850250 & $\begin{array}{l}\text { RGD, leucine rich repeat, tropomodulin, and proline-rich } \\
\text { containing protein }\end{array}$ & I & $3.6 \pm 2.1$ & No & unknown \\
\hline
\end{tabular}

D, decrease; I, increase.

a Relative RNA levels determined by quantitative RT-PCR.

\section{Learning \& Memory}

www.learnmem.org 
glycine alpha-amidating monooxygenase produces certain neuropeptides (Eipper et al. 1993). Thus, these molecules may modify memory extinction and/or synaptic plasticity.

Many previous studies focus on acquisition and storage of hippocampal-dependent memories, but very few focus on the molecular mechanisms underlying extinction (Abel and Lattal 2001). The data presented here indicate that CPEB-dependent post-transcriptional modifications are important, though not essential, for extinction of hippocampal-dependent memories. Polyadenylation in dendrites may provide a rapid mechanism to modulate synaptic strength that is necessary not only to acquire, but also to extinguish long-term memories. Many studies suggest that extinction of memories involves the hippocampus as well as the amygdala and prefrontal cortex (Maren and Quirk 2004), all of which contain CPEB (data not shown). Furthermore, extinction of hippocampal memories is likely to be protein synthesis dependent and may involve NMDA and cannabinoid receptors, as well as activation of a host of kinases (Cannich et al. 2004; Bevilaqua et al. 2005; Cammarota et al. 2005). While it is unclear which hippocampal proteins are important for the extinction of memories, the current study indicates that $\mathrm{CPEB}$, and those that are directly or indirectly under its control, may be involved in the synaptic tag that distinguishes a synapse to be extinguished from a naive one.

\section{Acknowledgments}

We thank Laura Schaevitz, Kristen Washington, Raya Terry, and Nupur Nag, who carried out some of the behavioral experiments, and Rebecca Hodgman for helping with the animal breeding. We also thank Gregory Quirk and Ted Abel for helpful discussions of the preliminary data, and Gilles Martin for brain dissections. R.N.Z. was supported by an NIH postdoctoral fellowship. This work was supported by grants from the NIH (to J.D.R.), and a faculty grant from Wellesley College (to J.B.S.).

\section{References}

Abel, T. and Lattal, K.M. 2001. Molecular mechanisms of memory acquisition, consolidation and retrieval. Curr. Opin. Neurobiol. 11: $180-187$.

Alarcon, J.M., Hodgman, R., Theis, M., Huang, Y.S., Kandel, E.R., and Richter, J.D. 2004. Selective modulation of some forms of schaffer collateral-CA1 synaptic plasticity in mice with a disruption of the CPEB-1 gene. Learn. Mem. 11: 318-327.

Arters, J., Hohmann, C.F., Mills, J., Olaghere, O., and Berger-Sweeney, J. 1998. Sexually dimorphic responses to neonatal basal forebrain lesions in mice: I. Behavior and neurochemistry. J. Neurobiol. 37: 582-594.

Barnard, D.C., Ryan, K., Manley, J.L., and Richter, J.D. 2004. Symplekin and $x G L D-2$ are required for CPEB-mediated cytoplasmic polyadenylation. Cell 119: 641-651.

Bevilaqua, L.R., da Silva, W.N., Medina, J.H., Izquierdo, I., and Cammarota, M. 2005. Extinction and reacquisition of a fear-motivated memory require activity of the Src family of tyrosine kinases in the CA1 region of the hippocampus. Pharmacol. Biochem. Behav. 81: 139-145.

Cammarota, M., Bevilaqua, L.R., Rossato, J.I., Ramirez, M., Medina, J.H., and Izquierdo, I. 2005. Relationship between short- and long-term memory and short- and long-term extinction. Neurobiol. Learn. Mem. 84: $25-32$.

Cannich, A., Wotjak, C.R., Kamprath, K., Hermann, H., Lutz, B., and Marsicano, G. 2004. CB1 cannabinoid receptors modulate kinase and phosphatase activity during extinction of conditioned fear in mice. Learn. Mem. 11: 625-632.

Du, L. and Richter, J.D. 2005. Activity-dependent polyadenylation in neurons. RNA 11: 1340-1347.

Eipper, E.A., Milgram, S.L., Husten, E.J., Yun, H., and Mains, R.E. 1993 Peptidylglycine $\{\alpha\}$-amidating monooxygenase: A multifunctional protein with catalytic, processing, and routing domains. Protein Sci. 2: 489-497.

Frick, K.M. and Berger-Sweeney, J. 2001. Spatial memory and neocortical neurochemistry vary with the estrous cycle in mice. Behav. Neurosci. 115: 229-237.

Frick, K.M., Burlingame, L.A., Arters, J.A., and Berger-Sweeney, J. 2000. Effects of age and sex in C57B1/Nia mice: I. Reference memory, sensorimotor ability, and estrous cyclicity. Neuroscience 95: 293-307.
Garcia, J.A., Zhang, D., Estil, S., Michnoff, C., Rutter, J., Reick, M., Scott, K., Ciaz-Arrastia, R., and McKnight, S.L. 2000. Impaired and contextual memory in NPAS2-deficient mice. Science 288: 2226-2230.

Hering, H. and Sheng, M. 2001. Dendritic spines: structure, dynamics and regulation. Nat. Rev. Neurosci. 2: 880-888.

Huang, Y.S., Jung, M.Y., Sarkissian, M., and Richter, J.D. 2002. $\mathrm{N}$-methyl-D-aspartate receptor signaling results in Aurora kinase-catalyzed CPEB phosphorylation and $\alpha$ CaMKII mRNA polyadenylation at synapses. EMBO J. 21: 2139-2148.

Huber, K.M., Kayser, M.S., and Bear, M.F. 2000. Role for rapid dendritic protein synthesis in hippocampal mGluR-dependent long-term depression. Science 288: 1254-1257.

Jero, J., Coling, D.E., and Lalwani, A.K. 2001. The use of Preyer's reflex in evaluation of hearing in mice. Acta Otolaryngol. 121: 585-589.

Kang, H. and Schuman, E.M. 1996. A requirement for local protein synthesis in neurotrophin-induced hippocampal synaptic plasticity. Science 273: 1402-1406.

Lattal, K.M. and Abel, T. 2001. Different requirements for protein synthesis in acquisition and extinction of spatial preferences and context-evoked fear. J. Neurosci. 21: 5773-5780.

Laurikkala, J., Kassai, Y., Pakkasjarvi, L., Thesleff, I., and Itoh, N. 2003. Identification of a secreted BMP antagonist, ectodin, integrating BMP, FGF, and SHH signals from the tooth enamel knot. Dev. Biol. 264: $91-105$.

Lein, P.J., Beck, H.N., Chandrasekaran, V., Gallagher, P.J., Chen, H.L., Lin, Y., Guo, X., Kaplan, P.L., Tiedge, H., and Higgins, D. 2002. Glia induce dendritic growth in cultured sympathetic neurons by modulating the balance between bone morphogenetic proteins (BMPs) and BMP antagonists. J. Neurosci. 22: 10377-10387.

Maren, S. and Quirk, G.J. 2004. Neuronal signalling of fear memory. Nat. Rev. Neurosci. 5: 844-852.

Martin, K.C., Barad, M., and Kandel, E.R. 2000. Local protein synthesis and its role in synapse-specific plasticity. Curr. Opin. Neurobiol. 10: 587-592.

Mendez, R., Hake, L.E., Andresson, T., Littlepage, L.E., Ruderman, J.V., and Richter, J.D. 2000. Phosphorylation of CPE binding factor by Eg2 regulates translation of c-mos mRNA. Nature 404: 302-307.

Moolenaar, W.H., van Meeteren L.A., and Giepmans, B.N. 2004. The ins and outs of lysophosphatidic acid signaling. Bioessays 26: 870-881.

Morris, R.G.M., Garrud, P., Rawlins, J.N.P., and O'Keefe, J. 1982. Place navigation impaired in rats with hippocampal lesions. Nature 297: 681-683.

Pähkla, R., Kask, A., and Rägo, L. 2000. Differential effects of $\beta$-carbolines and antidepressants on rat exploratory activity in the elevated zero-maze. Pharmacol. Biochem. Behav. 65: 737-742.

Richter, J.D. and Lorenz, L.J. 2002. Selective translation of mRNAs at synapses. Curr. Opin. Neurobiol. 12: 300-304.

Sanders, M.J., Wiltgen, B.J., and Fanselow, M.S. 2003. The place of the hippocampus in fear conditioning. Eur. J. Pharmacol. 463: 217-223.

Sarkissian, M., Mendez, R., and Richter, J.D. 2004. Progesterone and insulin stimulation of CPEB-dependent polyadenylation is regulated by Aurora A and glycogen synthase kinase-3. Genes \& Dev. 18: $48-61$.

Scheetz, A.J., Nairn, A.C., and Constantine-Paton, M. 2000. NMDA receptor-mediated control of protein synthesis at developing synapses. Nat. Neurosci. 3: 211-216.

Shin, C.Y., Kundel, M., and Wells, D.G. 2004. Rapid, activity-induced increase in tissue plasminogen activator is mediated by metabotropic glutamate receptor-dependent mRNA translation. J. Neurosci. 24: 9425-9433.

Sousa, J.C., Grandela, C., Fernandez-Ruis, J., de Miguel, R., de Sousa, L., Magalhaes, A.I., Saraiva, M.J., Sousa, N., and Palha, J.A. 2004 Transthyretin is involved in depression-like behaviour and exploratory activity. J. Neurochem. 88: 1052-1058.

Stein, T.D., Anders, N.J., DeCarli, C., Chan, S.L., Mattson, M.P., and Johnson, J.A. 2004. Neutralization of transthyretin reverses neuroprotective effects of secreted amyloid precursor protein (APP) in $\mathrm{APP}_{\mathrm{Sw}}$ mice resulting in $\tau$ phosphorylation and loss of hippocampal neurons: Support for the amyloid hypothesis. $J$. Neurosci. 24: 7077-7717.

Stork, O., Stork, S., Pape, H.C., and Obata, K. 2001. Identification of genes expressed in the amygdala during the formation of fear memory. Learn. Mem. 8: 209-219.

Tay, J. and Richter, J.D. 2001. Germ cell differentiation and synaptonemal complex formation are disrupted in CPEB knockout mice. Dev. Cell 1: 201-213.

Wu, L., Wells, D., Tay, J., Mendis, D., Abbott, M.A., Barnitt, A., Quinlan, E., Heynen, A., Fallon, J.R., and Richter, J.D. 1998. CPEB-mediated cytoplasmic polyadenylation and the regulation of experiencedependent translation of $\alpha$-CaMKII mRNA at synapses. Neuron 21: $1129-1139$.

Received August 31, 2005; accepted in revised form November 3, 2005. 


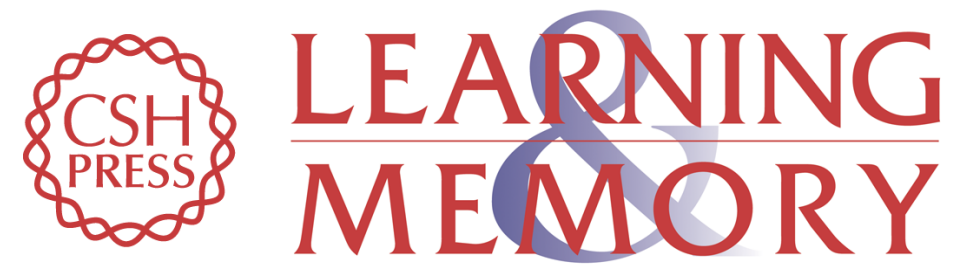

\section{Reduced extinction of hippocampal-dependent memories in CPEB knockout mice}

Joanne Berger-Sweeney, N. Ruth Zearfoss and Joel D. Richter

Learn. Mem. 2006, 13:

Access the most recent version at doi:10.1101/lm.73706

References This article cites 36 articles, 12 of which can be accessed free at: http://learnmem.cshlp.org/content/13/1/4.full.html\#ref-list-1

License

Email Alerting Receive free email alerts when new articles cite this article - sign up in the box at the Service top right corner of the article or click here. 